\title{
Arctic Haze and the Radiation Balance
}

Francisco P.J. Valero and Thomas P. Ackerman

$\begin{array}{lrrrr}\text { (NASA-TM-86784) ARCTIC HAZE AND THE } & & \text { N87-20 } \\ \text { EADIATION BALANCE (NASA) } & 30 \mathrm{p} & \text { CSCL 03A } & \\ & & & & \text { UnClas } \\ & & & \text { G3/88 } & 43549\end{array}$

December 1985 
NASA Technical Memorandum 86784

\section{Arctic Haze and the Radiation Balance}

Francisco P. J. Valero,

Thomas P. Ackerman, Ames Research Center, Moffett Field, California

December 1985

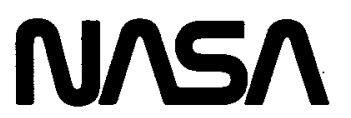

National Aeronautics and

Space Administration

Ames Research Center

Moffett Field, California 94035 


\section{ABSTRACT}

Airborne measurements of the absorption of solar radiation by the Arctic haze indicate atmospheric heating rates of from 0.15 to $0.25 \mathrm{Kday}^{-1}$ ( $24 \mathrm{hr}$ weighted averages) at latitudes between $72.6 \mathrm{~N}$ and $74.0 \mathrm{~N}$ during the early spring (March 15April 4, 1983).

The haze interaction with solar radiation alters the radiative balance of the atmosphere-surface system. Generally, this interaction results in an increase of the solar energy absorbed by the atmosphere and in a decrease of the radiation absorbed by the ground (ice or water). The effective planetary albedo is also affected, increasing for haze over water and decreasing for haze over ice.

The haze interaction with infrared (planetary) radiation has not been measured. However, the infrared component of the energy budget represents one of the most important contributions to the overall energy balance. Calculations can provide some information, but experimental evidence is required (at least to validate the calculations) because of the enhanced concentration of greenhouse gases measured in the haze layers.

The cumulative deposition of black carbon over the surface, produces a change in the optical properties of the ice which may result in an accelerating rate of ice melt. Experimental evidence of the magnitude of this effect is necessary to properly evaluate its consequences. An extended monitoring program is suggested. The significance of energy budget changes induced by the Arctic aerosol on climate depends on the spatial and temporal properties of the haze layers. Therefore, an important concern with climatic studies done using available measurements is with truly sampling the spatial and temporal properties of the haze layers. Do a few episodic airborne experiments (sort of a snapshot approach) yield information representative enough to be useful for building a sufficient understanding for climate studies?

\section{INTRODUCTION}

One would expect that the polar regions are a clean, pristine, environment. This is true in Antarctica, but the atmosphere in the northern polar regions, which is clean and clear during the summer, becomes heavily polluted with anthropogenic particles (aerosols) and gases during the winter. In 1957, Mitchell reported his findings on the "Visual Range in the Polar Regions with Particular Reference to the Alaskan Arctic." Mitchell (1957) notes that the Arctic aerosol was composed of nonice particles of sizes less than $2 \mu \mathrm{m}$. He also observed that a significant 
degradation in visibility occurs during the periods of heavy pollution (haze events). About fifteen years later, Shaw (1975) confirmed quantitatively that the atmosphere became very turbid during haze events. Shaw's measurements were done near Barrow, Alaska and at that time the origin of the haze was uncertain. Recent studies of the Arctic aerosol (Rahn and McCaffrey, 1980; Shaw and Stamnes, 1980; Rahn et al., 1977; Barrie et al., 1981; Heintzenberg et al., 1982) and the series of papers published in the Arctic Haze special issue of Geophysical Research Letters (May 1984) have reported the presence of large concentrations of aerosols in the Arctic atmosphere and discuss its possible impact on Earth's radiative balance and climate. The temporal behavior of the haze is characterized by a remarkable increase in density every winter, from about November through April, with a maximum in the period between late winter and early spring. This temporal behavior is governed by air-flow patterns, and by the lack of precipitation, which encourages the accumulation of aerosols in the atmosphere during the winter months. Figure 1 shows a photograph taken during an Arctic haze event in March 1983.

It has been shown (Rahn and McCaffrey, 1980) that the air pollution which permeates the Arctic during the winter originates in industrialized regions in the Soviet Union, Europe, and the United Kingdom, with minor contributions from North America. It has also been found that haze events are accompanied by an increase in the concentration of trace gases that originate in combustion processes, such as those associated with power and industrial plants (Khalil and Rasmussen, 1984).

From the climatic point of view, the interaction of solar and infrared radiation with the polluted atmosphere-surface system must be considered. The Arctic aerosols interact with solar radiation mostly during the late winter, early spring period when the aerosol concentration is at or near its maximum and the Sun elevation is sufficient for a significant amount of solar radiation to reach the Arctic. The interaction of solar radiation with the haze results in radiation being scattered and absorbed in the atmosphere. Shaw (1982) and Bodhaine et al. (1984) have determined high optical depths and Valero et al. (1983, 1984) have measured "in situ" the absorption of radiation by the haze. Rosen et al. (1981) reported that graphitic carbon (soot) is an important component of the Arctic aerosol. Most of the absorption of solar energy by the aerosol is attributable to the soot (Rosen and Novakov, 1981; Rosen and Hansen, 1984). The absorption of solar radiation by the haze is incremented by the fact that a large portion of the radiation reaching the ice surface (which acts like a mirror reflecting about $80 \%$ of the solar energy that touches it; water reflects only about 5\%-15\%) is reflected back into the atmosphere. Consequently, the reflected radiation passes through the haze layers for a second time resulting in additional absorption. As more energy is retained by the soot, an enhanced warming of the atmosphere takes place.

The combined effect of increased light scattering and absorption in the atmosphere results in a diminished amount of solar energy reaching the ground. The change in the energy absorption profile in the atmosphere (which is a function of the haze vertical structure) further modifies the energetics of the atmospheresurface system. It is clear that this redistribution of the radiation budget 
between the atmosphere and the surface may have consequences in climate and in the dynamics of the Arctic atmosphere.

The processes described above may be further compounded by the potentially important effect of the deposition of black carbon over the ice-snow surface. This could result in larger absorption by the surface, particularly after the haze season is over and could extend into the summer months, when the sunlight reaches the ground with maximum intensity. This would lead to a higher, self-accelerating rate of ice melt. As the top layers of ice melt, the soot deposited in previous seasons appears on the surface with a net result of an ever increasing number of soot particles being exposed to the solar radiation. If this cumulative process continues year after year, the result may be an accelerating rate of ice melt which has the potential to move the ice cap boundaries northward, thus reducing the extent of the insulating ice cover and opening up the ocean as an additional heating source. Not much work has been done on the surface effects of the Arctic Haze, but the potential for significant changes is there.

Finally, no infrared radiation measurements or calculations have been made. The infrared contribution to the radiation balance is generally considered to be minor. However, the increased concentration of pollution-related gases $\left(\mathrm{HNO}_{3}\right.$, hydrocarbons, etc.) with strong spectral bands in the 10-15 $\mu \mathrm{m}$ region (greenhouse gases)--in the neighborhood of the blackbody emission peak at Arctic atmosphere temperatures--may result in an additional mechanism influencing the Arctic energy budget. Furthermore, atmospheric infrared radiative effects of the haze take place through the winter months, and the surface effects persist all year long. The time scale of the infrared processes is such that their overall influence may not be trivial when compared to solar radiation.

In'this paper, we focus on the absorption of solar radiation by the Arctic haze and on its vertical structure as determined from net flux measurements. We deduce the perturbations introduced by the haze in the solar energy distribution in the atmosphere-ground system, and determine the haze-induced changes in the atmospheric heating rates as a function of altitude. New radiation measurements are also suggested to confirm and improve our present understanding of the Arctic energetics. We emphasize the need for a program to monitor possible changes (caused by the cumulative deposition of the black aerosols) in the ability of the ice cap to reflect light.

\section{EXPERIMENTAL CONCEPTS AND MEASUREMENTS}

As discussed above, an important aspect of the Arctic haze is its effect on the Earth's energy budget. This effect can be studied by collecting samples of the haze and then measuring its optical properties in the laboratory. A different approach is to measure the absorption by the polluted atmosphere "in situ." From the comparison of the energy absorbed by the atmosphere during haze events and the energy absorbed by the haze-free atmosphere, one can determine the effect of the Arctic 
haze on the solar energy budget. To determine "in situ" the magnitude of the absorption of solar radiation by the aerosol, we proceeded to measure radiative flux densities at different altitudes in the atmosphere and from these measurements, we determined the energy absorbed in the atmospheric layer included between flight levels. This can be done by measuring the upwelling ( $u$ ) and down-welling (d) radiative flux densities at various altitudes ( $h$ ) within the atmosphere (see figure 2 ). The difference between $d(h)$ and $u(h)$ gives the net flux density at altitude $h$; the difference between the net fluxes at two altitudes ( $A$ in $f i g .2$ ) is the radiative flux density absorbed by the atmospheric layer included between measuring altitudes.

Atmospheric gases, including water vapor, absorb light only at particular wavelengths (spectral features); on the other hand, the haze acts as a grey body and absorbs energy at practically all wavelengths. If one would measure the radiative flux densities in the atmosphere for a broad spectral bandpass (including all wavelengths), the result would be the radiative flux density absorbed by all components of the atmosphere including gases and aerosols. During AGASP I, we were interested in measuring the absorption of solar energy by the haze itself when immersed in the atmospheric environment, independently from the contributions by atmospheric gases to the total absorption. This can be done by selecting wavelength intervals where it is known that atmospheric gases do not absorb. In this way, any absorption measured in these narrow wavelength intervals can be attributed exclusively to absorption by the haze. With proper data analysis and modeling, the absorption of radiation by the aerosol at all wavelengths can be determined from the measurements in narrow spectral intervals. Once one knows how much flux density is absorbed in the atmosphere, it is a simple matter to determine the resulting heating profiles in the atmosphere.

A way to verify the results from the above-described approach is to simultaneously measure the broadband of total absorbed radiation. It can be shown that if we substract the portion attributable to gases from the total energy absorbed by the atmosphere, what is left is the absorption by the haze. The spectral parameters that describe the absorption by gases and water vapor are known from laboratory spectroscopy. With this information, the portion of the flux density absorbed by the haze can be calculated. A comparison of the two results (broadband and narrow spectral bandpasses approaches) offers a way to check the consistency of the results.

To perform the radiation measurements described in the previous paragraph, we designed and built a special radiometric system that was installed in the NOAA WP-3D Orion research aircraft and used during AGASP I (see fig. 3). The radiometric system consists of three narrow, one intermediate, and one broad spectral bandpass channels. All channels have a hemispherical field of view. These hemispherically integrating radiometers were mounted in a rotor installed in the right wing tip of the aircraft. The rotating arrangement exposed each radiometer alternately to upwelling and downwelling radiative fluxes. Differencing the upward- and downwardlooking measurements, done using the same radiometer, minimizes the systematic errors in the system and provides a direct measurement of the net flux density crossing a plane parallel to the flightpath of the aircraft. As explained above, 
the difference between net fluxes at different altitudes gives the absorption by the atmospheric column included between net flux measurement altitudes.

The wavelengths selected for the three narrow $(0.01 \mu \mathrm{m})$ spectral bandpass channels were centered at $0.485,0.680$, and $0.860 \mu \mathrm{m}$; the one intermediate $(0.08 \mu \mathrm{m})$ bandpass channel was centered at $0.940 \mu \mathrm{m}$ (to monitor the concentration of water vapor), and the broad spectral bandpass channel covered the region from 0.26 to $2.6 \mathrm{~m}$. This radiometric system is sufficient to apply the methods described above.

The radiative net fluxes at different altitudes were measured by flying profiles similar to the one illustrated in figure 4. The measurements were done around noon in order to minimize the effects of changes in Sun elevation with time. (At polar latitudes, the Sun elevation changes very slowly and the corresponding corrections did not exceed $2 \%$ in any case.)

\section{RESULTS}

\section{a) Narrow Spectral Bandpass Radiometers}

Figure 5(a), (b), and (c) depicts the narrow band flux density absorption as measured during AGASP flights 3,4 , and 8 , respectively.

Column 1 of table 1 shows the altitudes $h$ at which measurements of the radiative flux were made; column 2 shows the thicknesses $\Delta h$ of the atmospheric layers between the altitudes of column 1; the quantities in column 3 are the mean altitudes $\bar{h}$ of the layers. Column 4 shows the identification numbers assigned to each layer. The ordinate in figure 5 refers to the radiative flux density absorbed in watts $/ \mathrm{m}^{2}$ for a $0.01 \mu \mathrm{m}$ spectral bandpass; it applies to atmospheric layers of thickness $\Delta h$ and mean altitude $\bar{h}$, as identified in table 1 . Table 2 shows the measured values that correspond to the radiative flux density absorbed by each atmospheric layer during each of the AGASP flights discussed in this paper.

Here, we report only measurements obtained under cloud-free conditions. AGASP flights 3 and 4 were over the western Arctic and were made on March 15 and 17, 1983, respectively. The flux measurements were centered at $72.6^{\circ} \mathrm{N}$ latitude and $156.9^{\circ} \mathrm{W}$ longitude. The measured albedo (reflectivity) of the overflown ice surface was 0.75. AGASP flight 8 was over the eastern Arctic and was made on March 31, 1983. The flux measurements were centered at $74.0^{\circ} \mathrm{N}$ latitude and $25.0^{\circ} \mathrm{E}$ longitude. Some broken clouds were encountered during this flight but those portions of the flight are omitted from this analysis. The albedo of the open ocean was measured as 0.15 . This high albedo value was presumably a result of the large contribution of specular reflection at these large solar zenith angles.

To compute the heating rates produced by the absorption of solar radiation, we extended the narrow-band spectral measurements to all solar wavelengths using the following procedure: An approximate aerosol model, consistent with ground-based data on Arctic haze (Heintzenberg et al., 1981; Heintzenberg, 1980; Rosen et al., 
1981; Bodhaine et al., 1981) was constructed. The aerosol was assumed to be an external mixture of sulfate and carbon and had a single-scattering albedo of 0.8 at $0.5 \mathrm{~m}$. This aerosol was then incorporated in a multilayer version of the deltafour-stream model described by Cuzzi et al. (1982).

For simplicity in the case of the narrow bandpass channels, we modeled the haze as a single layer, uniformly mixed with height. Based on particle counter data, the haze layer was defined to be $3 \mathrm{~km}$ thick for AGASP flight 4 , and $5 \mathrm{~km}$ thick for AGASP flights 3 and 8 . In addition, a nonabsorbing stratospheric aerosol layer of optical depth 0.1 (Dutton et al., 1984) was placed at $10 \mathrm{~km}$. Model calculations were carried out for various values of the aerosol optical depth for the three wavelengths corresponding to the narrow-band radiometer channels for each of the three flights. The surface albedo in each case was determined from the radiometer measurements at the lowest flight level. The results of these calculations are shown in figure 6.

It is apparent that a good agreement can be obtained in each case between the measured absorption and the calculated absorption. In the case of AGASP 3, some ground optical depth information was available from the Barrow monitoring facility operated by NOAA. These measured optical depths agree well with the values determined here, but an exact comparison is difficult because of the presence of stratospheric aerosol and the spatial variations of the haze. It should be noted that the calculation of absorbed energy is sensitive primarily to the amount of black carbon included in the aerosol model. The carbon is relatively insensitive to the nonabsorbing aerosol component and to the assumed aerosol microphysics. Consequently, the agreement exhibited in figure 6 is indicative only of a correct choice of the amount of black carbon.

Using the aerosol properties determined by fitting the measurements, the model was run for 26 spectral intervals covering the range of 0.25 to $4.3 \mu \mathrm{m}$. Profiles of gaseous absorbers were taken from the subarctic winter profile of McClatchey et al. (1972). The instantaneous heating rates computed for the three flights are given in table 3. For comparison purposes, we have also computed the heating rate in the absence of haze aerosols and the ratio of the two heating rates. To better understand the role of the haze, the results of a calculation done for flight 8 with a high-albedo surface $\left(A_{S}=0.75\right)$ are also included, and is representative of the effects of a thick haze layer over the ice-covered Arctic basin.

\section{b) Broad Spectral Bandpass Radiometer}

In this section, we report the results obtained from the broadband channel measurements. One objective of these measurements is to use them as a verification of the results presented in a); another important objective is to determine the radiative transfer changes introduced by the Arctic haze relative to an "average" standard Arctic atmosphere. For example, if water vapor concentrations are in some way correlated with haze concentrations or haze absorption properties (as may or may not be the case), our concern, then, is to investigate "in situ" the combined, 
integrated effects on the absorption of radiation by all atmospheric components during haze events, and their relationship to average standard conditions.

Table 4 presents the results of the broadband measurements for AGASP flights 3 and 8 ; the values of absorbed power per unit area presented in column 4 were used to calculate the heating rates for each atmospheric layer. This was done using the conventional expression, in pressure coordinates, for the heating rate for an atmospheric layer thickness $\Delta P$ (Liou, 1980):

$$
\frac{\partial T}{\partial P}=\frac{g}{C_{p}} \frac{\Delta F(\Delta P)}{\Delta P}
$$

where $T$ is temperature $(X), t$ is time, $g$ is the gravitational acceleration, $C_{P}$ is the specific heat at constant pressure, $\Delta F$ is the radiative energy absorbed, and $\Delta \mathrm{P}$ is the pressure differential between the top and bottom of the atmospheric layer under consideration. The values of the heating rates obtained using equation (1) are shown in column 5 of table 4. Figure 7 depicts the radiative power absorbed by the atmosphere as a function of altitude and the corresponding heating rates, respectively.

In order top compare the haze and no-haze heating rates, we calculated heating rates for a representative Arctic winter atmosphere in the absence of haze. The results of these calculations are shown, for individual atmospheric layers, in column 6 of table 4. The water vapor profiles obtained from the standard instrumentation of the aircraft (Schnell and Raatz, 1984; Raatz and Schnell, 1984) and the data from the 940-nm spectral channel, dedicated to monitor water vapor absorption (Valero et al., 1983), were used to compute the values in column 7 of table 4 that shows the heating rates that correspond to a haze-free atmosphere with the water vapor concentrations determined as described above. Figure 8 presents the flux density absorbed by the haze and the corresponding haze heating rates for each atmospheric layer. Table 5 shows the broadband flux density absorbed in each layer and corresponding daily averaged heating rates. Table 6 presents a comparison of heating rates as determined from broad and narrow spectral bandpasses.

\section{c) The Vertical Structure of the Arctic Haze}

By differencing the net flux values at the various altitudes and comparing these values to model calculations, we can deduce the aerosol optical depth for each of the three layers defined by the flight altitudes. These values are also tested for consistency by comparing the narrow and broadband measurements. In addition, using the optical depth values and the carbon column values of Rosen and Hansen (1984), we can infer the "in situ" specific absorption of carbon.

The model described in a previous section was used to infer the aerosol optical depths for flights 3 and 8 by computing the absorbed power per layer in three narrow-band channels. The calculations were iterated for several extinction optical 
depth profiles until good agreement with the measurements was obtained. Since the aerosol optical properties are fixed in the model, this is essentially equivalent to varying the absorption optical depth, $\tau_{a}$. Multiple-scattering is included but is a second-order effect owing to the relatively modest aerosol optical depths being considered.

In figure 9, the computed energy absorption in the three narrow-band channels is compared to the measured values for both flight 3 and flight 8 . For flight 3 , the inferred total haze optical depth at $0.55 \mu \mathrm{m}$ is 0.27 . Of this, 0.03 is in layer $1(3.9-7.0 \mathrm{~km}), 0.09$ is in layer $2(1.6-3.9 \mathrm{~km})$, and 0.15 in layer 3 $(0-1.6 \mathrm{~km})$. For flight 8 , the total optical depth is 0.31 , with $0.03,0.09$, and 0.19 in layers 1,2 , and 3 , respectively. The good agreement between the model results and the data is primarily indicative of a correct choice of $\tau_{a}$, since the measurements constrain the absorption. The total optical depth is then constrained by the single-scattering albedo which we have fixed. Since, in reality, this albedo may plausibly lie roughly between 0.70 and 0.90 , the total optical depth values have an uncertainty of $10 \%$ to $15 \%$. As expected, the wavelength dependence of the absorption is consistent with a broadband absorber such as black carbon. Thus, we can conclude from this comparison that the absorption optical depth, $\tau_{a}$, for the aerosol for the three layers was $0.007,0.020$, and 0.033 for flight 3 , and $0.007,0.020$, and 0.041 for flight 8 .

The computed and measured broadband $(0.26$ to $2.6 \mu \mathrm{m})$ energy absorption as a function of layer for both flights is presented in table 7. The calculations were carried out using the same aerosol model and the optical depth values given above, which were determined from the narrow band measurements. The agreement between the measurements and the calculations is remarkably good, both for the total absorption in the haze and for the absorption in the individual layers. This is further proof that the aerosol absorption optical depths deduced from the narrow-band data are correct, and that the wavelength dependence of the aerosol absorption is indeed broadband.

From the results presented above, we can conclude that during both these flights the majority of the absorbing aerosol was located between the surface and $1.6 \mathrm{~km}$. For flight $8,10 \%$ of the aerosol absorption optical depth is in layer 1 , $29 \%$ in layer 2 , and $61 \%$ in layer 3 , which is the lowest layer. We have assumed that this absorbing aerosol is predominantly black carbon. Rosen and Hansen (1984) have reported measurements of graphitic (or black) carbon concentration as a function of altitude for flight 8 . These measurements cover the same altitude range ( 0 to $7 \mathrm{~km}$ ) as our net-flux measurements and have a higher vertical resolution. We have integrated the vertical profile given in figure 3 of their paper and find that $14 \%$ of their total column concentration is located in layer $1,35 \%$ in layer 2 , and $51 \%$ in layer 3. Given the considerable difference between the two experiments in terms of the quantities being measured, the temporal and spatial resolution, the experimental techniques, as well as the uncertainties involved in both sets of measurements and the model results, the agreement between the percentages is quite good.

The results of Rosen and Hansen (1984) and those presented here can be used to infer a specific absorption for black carbon in the Arctic atmosphere. The total 
column amount of carbon measured by Rosen and Hansen (1984) is $0.0028 \mathrm{~g} / \mathrm{m}^{2}$. From the model, we infer the value of $\tau_{a}=0.068$. The specific absorption is found by dividing $\tau_{a}$ by the total column amount, which gives a value of $24 \mathrm{~m}^{2} / \mathrm{g}$. This is a somewhat surprising value since the generally accepted value for black carbon is on the order of $8-10 \mathrm{~m}^{2} / \mathrm{g}$ (Roessler and Faxfog, 1980; Szkarlat and Japar, 1981). There are several possible explanations for this large specific absorption. One is that the model has grossly overestimated the value of $\tau_{a}$ because of an incorrect aerosol model. As we have noted above, this is unlikely. The measurements effectively constrain $\tau_{a}$ rather than the extinction optical depth. Thus a change in the aerosol model will have little effect on $\tau_{a}$.

A second is that the factor used by Rosen and Hansen (1984) to convert their optical attenuation data to black carbon concentration is incorrect. In view of their laboratory studies (Gundel et al., 1984), this also appears unlikely. Alternatively, Ackerman and Toon (1981) have shown that it is possible to enhance the absorption per unit volume (or mass) of an aerosol particle by surrounding it with a nonabsorbing shell.

To illustrate this latter effect, we performed a series of calculations for particles composed of carbon cores and sulfate shells using the particle size distribution assumed in this model for sulfate particles. The specific absorption per unit volume of carbon as a function of the volume fraction of carbon in the particles is shown in figure 10. To get values of the specific absorption per unit mass, one must divide by the density of the carbon in units of $\mathrm{g} / \mathrm{cm}^{3}$. It is apparent that we must assume a carbon density of approximately $1 \mathrm{~g} / \mathrm{cm}^{3}$ in order to get the specific absorption of pure carbon spheres to agree with the measured value of $8-10 \mathrm{~m}^{2} / \mathrm{g}$. Such a density is reasonable if the carbon volume is an aggregate of small spheres rather than a single, solid sphere, as is often the case (for examples, see Janzen, 1980, or Borghesi et al., 1983). Using this value of the density converts the ordinate of figure 9 to units of $\mathrm{m}^{2} / \mathrm{g}$. We can then infer from the figure that our value of $\tau_{a}$ is consistent with the black carbon amount of Rosen and Hansen (1981) if the carbon is present as an internal mixture and represents about $10 \%$ of the aerosol volume. While these assumptions would seem to be fairly plausible, they imply an aerosol with a single-scatter albedo on the order of 0.61 . This is smaller than that of the external mixture used in the model calculations above and smaller than that deduced from the surface measurements of Rosen et al. (1981) and Bodhaine et al. (1981). The use of the internal mixture in the model leads to a reduction in the aerosol extinction optical depth from 0.31 to 0.18 , but causes essentially no change in the value of $t_{a}$. The correct choice of aerosol model cannot be resolved at this time, but further analysis of the data collected on the AGASP flights may lead to new insights.

\section{DISCUSSION AND CONCLUSIONS}

It is clear that heating rate changes of the magnitude found have the potential to significantly modify the local climate and possibly influence the climate at 
mid-latitudes. At the present time, it is not possible for us to completely assess the actual climatic effects of the radiation-haze interaction in the Arctic. However, an indication of the consequences of these effects on the energy budget can be inferred from considering the modifications introduced by the haze both in the total radiative energy absorbed by the atmosphere-surface system and in the resulting changes in the distribution of the absorbed energy between the atmosphere and the surface. This can be done using the data obtained during flights 3 and 8 . Flight 3 took place over an ice surface, and the broadband albedo measured during the lowest altitude path was 0.78 . For flight 8 , over the ocean, albedo measured was 0.13 .

Using the measured albedos, the measured energy absorbed by the atmosphere, and the calculated energy absorption for no-haze conditions (the same values used to determine the calculated heating rates for no-haze conditions), one can estimate how the energy budget and the distribution of absorbed energy between the atmosphere and the surface change with the haze and the two types of surface conditions. Such analysis shows that the presence of haze modified the energy budget and distribution as follows:

1. For haze over ice (flight 3 , March $15,1983,72.6^{\circ} \mathrm{N}$ latitude, $156.9^{\circ} \mathrm{W}$ long i tude.

a. Increased the total flux density absorption in the atmospheric layer between 7 and $0.03 \mathrm{~km}$ altitude from approximately $36 \mathrm{wm}^{-2}$ to $77 \mathrm{wm}^{-2}$.

b. Decreased the flux density absorbed by the ice surface itself from $54 \mathrm{wm}^{-2}$ to $43 \mathrm{wm}^{-2}$.

c. Increased the total absorption of radiative solar flux density by the atmosphere-surface system ( 7 to $0.03 \mathrm{~km}$ altitude) from approximately $90 \mathrm{wm}^{-2}$ to $122 \mathrm{wm}^{-2}$.

d. Reduced the effective planetary albedo by about $9 \%$ (from $63 \%$ to $54 \%$ ) at the given location.

2. For haze over water (flight 8, March $31,1983,74.0^{\circ} \mathrm{N}$ latitude, $25.0^{\circ} \mathrm{E}$ longitude.

a. Increased the total flux density absorption in the atmospheric layer between 7 and $0.03 \mathrm{~km}$ from about $40 \mathrm{wm}^{-2}$ to $79 \mathrm{wm}^{-2}$.

b. Decreased the flux density absorbed by the water surface from about $257 \mathrm{wm}^{2}$ to $202 \mathrm{wm}^{-2}$.

c. Decreased the total absorption of solar radiation by the atmosphere surface system ( 7 to $0.03 \mathrm{~km}$ altitude) from $297 \mathrm{wm}^{-2}$ to $285 \mathrm{wm}^{-2}$.

d. Increased the effective planetary albedo by about $2.5 \%$ (from $21.8 \%$ to 24.3\%) at the given location. 
The results described above demonstrate the potential effect of the Arctic haze on the Arctic energy budget. The heating rates are comparable to those computed in earlier purely theoretical studies (e.g., Porch and MacCraken, 1982). However, the absorbed energy is actually greater than that found in those studies, primarily because of the larger optical depths found during AGASP. It is also important to note that the vertical extent of the haze layers during AGASP I was considerably greater than had been anticipated by those studies. The exact effect of these perturbations in the energy budget is difficult to assess using only a radiative model because of the complicated interaction with ice physics and atmospheric dynamics. Furthermore, we neglected one of the most complicated aspects of the problem, the interaction of the haze with clouds. The studies described here were all made for cloud-free atmospheres. Calculations that we have carried out indicate that the heating may be reduced if clouds overlie the haze. However, if the haze is mixed with the clouds, there is a potential enhancement of the absorption within the clouds.

From the analysis of our data, we also conclude that a new series of radiation measurements over the Arctic is necessary. Airborne Sun-photometry, infrared radiometry, and a total/diffuse ratio radiometer should be included as well as particle size measurements, size-segregated samples for black carbon analysis, and filter micrographs to see what particles look like. The information from these instruments will complement the flux density measurements, simplify the necessary corrections, and remove uncertainties from the model calculation. Also, a detailed, and extended program to measure surface albedo and its seasonal and annual changes should be contemplated since temporal changes in albedo, owing to cumulative deposition of black carbon over the ice, may introduce significant radiative effects in the solar and infrared regions of the spectrum.

The cumulative deposition of black carbon over the polar ice cap with its potential to alter the optical properties of the surface suggests the need for a detailed and extended program to monitor the seasonal and annual changes in the surface radiative properties. 


\section{REFERENCES}

Ackerman, T. P.; and Toon, O. B.: Absorption of Visible Radiation in Atmospheres Containing Mixtures of Absorbing and Nonabsorbing Particles. Appl. Opt., vol. 20, no. 20 , Oct. 15, 1981, pp. 3661-3668.

Ackerman, T. P.; and Valero, F. P. J.: The Vertical Structure of Arctic Haze as Determined From Airborne Net-Flux Radiometer Measurements. Geophys. Res. Lett., vol. 11, No. 5, May 1984, pp. 469-472.

Barrie, L. A.; Hoff, R. M.; and Daggupaty, S. J.: The Influence of Mid-latitudinal Pollution Sources on Haze in the Canadian Arctic. Atmos. Environ,, vol. 15, no. 8, 1981, pp. 1407-1419.

Bodhaine, B. A.; Harris, J. M.; and Herbert, G. A.: Aerosol Light Scattering and Condensation Nuceli Measurements at Barrow, Alaska. Atmos. Environ., vol. 15, no. 8,1981 , pp. 1375-1389.

Bodhaine, B. A.; Dutton, E. G.; and DeLuisi, J. J.: Surface Aerosol Measurements at Barrow during AGASP. Geophys. Res. Lett., vol. 11, no. 5, May 1984, pp. 377-380.

Borghesi, A.; Bussoletti, E.; Colangeli, L.; Minafra, A.; and Rubini, F.: The Absorption Efficiency of Submicron Amorphous Carbon Particles Between 2.5 and $40 \mathrm{\mu m}$, Infrared Phys., vol. 23, no. 2, Mar. 1983, pp. 85-92.

Cuzzi, J. N.; Ackerman, T. P.; and Helmle, L. C.: The Delta-Four-Stream Approximation for Radiative Flux Transfer. J. Atmos. Sci., vol. 39, no. 4, April 1982, pp. 917-925.

Dutton, E.; Deluisi, J. J.; and Bodhaine, B. A.: Features of Total Vertical Aerosol Optical Depth at Barrow, Alaska, 10-20 March 1983. Geophys. Res. Lett., vol. 11, no. 5, May 1984, pp. 385-398.

Gundel, L. A.; Dod, R. L.; Rosen, H. J.; and Novakov, T.: The Relationship Between Optical Attenuation and Black Carbon Concentration for Ambient and Source Particles, Science of the Total Environment, 1984 (in press).

Heintzenberg, J.; Hansson, H. C.; and Lannefors, H.: The Chemical Composition of Arctic Haze at Ny-Alesund, Spitzbergen. Tellus, vol. 33, no. 2, 1981, pp. $162-171$.

Heintzenberg, J.: Particle Size Distribution and Optical Properties of the Arctic Haze. Tellus, vol. 32, no. 3, 1980, pp. 251-260.

Heintzenberg, J.: Size-Segregated Measurements of Particulate Elemental Carbon and Aerosol Light Absorption of Remote Arctic Locations. Atmos. Environ., vol. 16, no. 10, 1982, pp. 2461-2469. 
Janzen, J.: Extinction of Light by Highly Nonspherical Strongly Absorbing Colloidal Particles: Spectrophotometric Determination of Volumn Distributions for Carbon Black. Appl. Opt., vol. 19, no. 17, Sept. 1, 1980, pp. 2977-2985.

Khalil, M. A. K.; and Rasmussen, R. A.: Analysis of Trace Gases in Arctic Haze. Geophys. Res. Lett., vol. 11, no. 5, May 1984, pp. 437-440.

Liou, K. N.: An Introduction to Atmospheric Radiation. Academic Press, New York, 1980 , p. 392.

McClatchey, R. A.; Fenn, R. W.; Selby, J. E. A.; Volz, F. E.; and Garing, G. S.: Optical Properties of the Atmosphere, AFCRL Report, 3d ed., 72-0197, 1972.

Mitchel, J. M., Jr.: Visual Range in the Polar Regions with Particular Reference to the Alaskan Arctic. J. Atmos. Terr. Phys., Spec. Suppl. Pt. 1, 1957, pp. 195-211.

Ottar, B.: The Transfer of Airborne Pollutants to the Arctic Region. Atmos. Environ., vol. 15, no. 8, 1981, pp. 1439-1445.

Porch, W. M.; and MacCracken, M. C.: Parametric Study of the Effects of Arctic Soot on Solar Radiation. Atmos. Environ., vol. 16, no. 6, 1982, pp. 1365-1371.

Raatz, W. E.; and Schnell, R. C.: Aerosol Distributions and an Arctic Aerosol Front During AGASP, Norwegian Arctic. Geophys. Res. Lett., vol. 11, no. 5, May 1984, pp. 373-376.

Rahn, K.; Borys, R.; and Shaw, G. E.: The Asian Source of Arctic Haze Bands. Nature, vol. 268, no. 5622, Aug. 25, 1977, pp. 713-715.

Rahn, K. A.; and McCaffrey, R. J.: On the Origin and Transport of the Winter Arctic Aerosol. Ann. N.Y. Acad. Sci., vol. 338, 1980.

Roessler, D. M.; and Faxfog, F. R.: Photoacoustic Determination of Optical Absorption to Extinction Ratio in Aerosols. Appl. Opt., vol. 19, no. 4, Feb. 15, 1980, pp. 578-581.

Rosen, H.; and Hansen, A. D. A.: Role of Combustion-Generated Carbon Particles in the Absorption of Solar Radiation in the Arctic Haze. Geophys. Res. Lett., vol. 11, no. 5, May 1984, pp. 461-464.

Rosen, H.; Novakov, T.; and Bodhaine, B. A.: Soot in the Arctic. Atmos. Environ., vol. 15, no. 8, 1981, pp. 1371-1374.

Rosen, H.; and Novakov, T.: Combustion-Generated Carbon Particles in the Arctic Atmosphere. Nature, vol. 306, no. 5945, Dec. 22, 1983, pp. 768-770. 
Schnell, R. C.: Arctic Haze and the Arctic Gas and Aerosols Sampling Program (AGASP). Geophys. Res. Lett., vol. 11, no. 5, May 1984, pp. 361-363.

Schnell, R. C.; and Raatz, W. E.: Vertical and Horizontal Characterization of Arctic Haze during AGASP, Alaskan Arctic. Geophys. Res. Lett., vol. 11, no. 5, May 1984, pp. 369-372.

Shaw, G. E.; and Stamnes, K.: Arctic Haze; Perturbation of the Polar Radiation Budget. Ann. N.Y. Acad. Sci., vol. 338, 1980, pp. 535-539.

Shaw, G. E.: Atmospheric Turbidity in the Polar Regions. J. Appl. Meteor., vol. 21, no. 8, Aug. 1982, pp. 1080-1088.

Shaw, G. E.: The Vertical Distribution of Atmospheric Aerosols at Barrow, Alaska. Tellus, vol. 27, no. 1, 1975, pp. 39-50.

Szkarlat, A. C.; and Japar, S. M.: Light Absorption by Airborne Aerosols: Comparison of Integrating Plate and Spectrophone Techniques. Appl. Opt., vol. 20, no. 7, Apr. 1981, pp. 1151-1155.

Valero, F. P. J.; Ackerman, T. P.; and Gore, W. J. Y.: Radiative Effects of the Arctic Haze. Geophys. Res. Lett., vol. 10, no. 12, Dec. 1983, pp. 1184-1187.

Valero, F. P. J.; Ackerman, T. P.; and Gore, W. J. Y.: The Absorption of Solar Radiation by the Arctic Atmosphere During the Haze Season and Its Effects on the Radiation Budget. Geophys. Res. Lett., vol. 11, no. 5, May 1984, pp. 465-468. 


\begin{tabular}{|c|c|c|c|}
\hline $\begin{array}{l}\mathrm{h}, \\
\mathrm{km}\end{array}$ & $\begin{array}{c}\Delta \mathrm{h} \\
\mathrm{km}\end{array}$ & $\begin{array}{l}\bar{h}, \\
\mathrm{~km}\end{array}$ & $\begin{array}{l}\text { Layer } \\
\text { number }\end{array}$ \\
\hline 7.0 & & & \\
\hline 3.9 & 3.1 & 5.45 & 1 \\
\hline 1.6 & 2.3 & 2.75 & 2 \\
\hline 0.03 & 1.57 & .81 & 3 \\
\hline
\end{tabular}

Notes:
$h=$ altitude at which flux measurements were made.
$\Delta h=$ thickness of atmosphere layer; $h=$ mean altitude. 
TABLE 2.- ABSORPTION OF RADIATIVE FLUX DENSITIES

\begin{tabular}{|c|c|c|c|c|}
\hline \multirow{2}{*}{$\begin{array}{l}\text { AGASP } \\
\text { flight }\end{array}$} & \multirow{2}{*}{$\begin{array}{l}\text { Layer } \\
\text { number }\end{array}$} & \multicolumn{3}{|c|}{ Flux density absorbed $\left(\mathrm{wm}^{-2}\right)$ at noon } \\
\hline & & $\begin{array}{l}\text { Channel A } \\
(0.485 \mu \mathrm{m})\end{array}$ & $\begin{array}{l}\text { Channel B } \\
(0.680 \mu \mathrm{m})\end{array}$ & $\begin{array}{l}\text { Channel C } \\
(0.860 \mu \mathrm{m})\end{array}$ \\
\hline \multirow[t]{3}{*}{3} & 1 & $0.15 \pm 0.02$ & $0.08 \pm 0.01$ & $0.07 \pm 0.01$ \\
\hline & 2 & $0.38 \pm 0.03$ & $0.25 \pm 0.02$ & $0.18 \pm 0.03$ \\
\hline & 3 & $0.55 \pm 0.05$ & $0.36 \pm 0.04$ & $0.28 \pm 0.03$ \\
\hline \multirow[t]{3}{*}{4} & 1 & --- & --- & --- \\
\hline & 2 & $0.27 \pm 0.03$ & $0.17 \pm 0.01$ & $0.11 \pm 0.01$ \\
\hline & 3 & $0.41 \pm 0.03$ & $0.28 \pm 0.03$ & $0.20 \pm 0.01$ \\
\hline \multirow[t]{3}{*}{8} & 1 & $0.14 \pm 0.01$ & $0.10 \pm 0.01$ & $0.05 \pm 0.01$ \\
\hline & 2 & $0.38 \pm 0.03$ & $0.23 \pm 0.01$ & $0.14 \pm 0.01$ \\
\hline & 3 & $0.54 \pm 0.03$ & $0.36 \pm 0.03$ & $0.23 \pm 0.02$ \\
\hline
\end{tabular}

Notes: Altitude and thickness of layers are given in table 1 ; spectral bandpass is $0.01 \mu \mathrm{m}$. 
TABLE 3.- DAILY AVERAGED HEATING RATES

\begin{tabular}{lcrrr}
\hline $\begin{array}{l}\text { AGASP } \\
\text { flight }\end{array}$ & $\begin{array}{l}\text { Best Fit, } \\
\left(\tau_{H}\right)^{a}\end{array}$ & $\begin{array}{c}\text { Heating Rates, } \\
\text { K/day }\end{array}$ & $\begin{array}{c}\text { Heat rate ratio, } \\
\text { haze/no-haze }\end{array}$ \\
\cline { 3 - 4 } & & Haze & No haze \\
\hline & & & \\
\hline 4 & 0.26 & 0.17 & 0.08 & 2.1 \\
8 & .17 & .19 & .07 & 2.7 \\
$8^{b}$ & .31 & .21 & .08 & 2.6 \\
& .31 & .27 & .10 & 2.7 \\
\hline
\end{tabular}

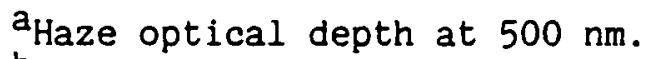

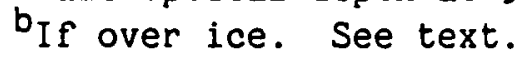


TABLE 4.- TOTAL RADIATIVE FLUX DENSITY ABSORPTION AND HEATING RATES

\begin{tabular}{|c|c|c|c|c|c|c|}
\hline \multirow[b]{2}{*}{$\begin{array}{l}\text { AGASP } \\
\text { flight } \\
\text { no. }\end{array}$} & \multirow{2}{*}{$\begin{array}{l}\text { Measured } \\
\text { broadband } \\
\text { surface } \\
\text { albedo }\end{array}$} & \multirow{2}{*}{ Layer $^{a}$} & \multirow{2}{*}{$\begin{array}{l}\text { Measured }^{b} \\
\text { flux density } \\
\text { absorption, } \\
\text { wm }^{-2}\end{array}$} & \multicolumn{3}{|c|}{ Calculated haze-free heating rates } \\
\hline & & & & $\begin{array}{c}\text { Measured } \\
\text { haze event } \\
\text { heating rate, } \\
\mathrm{Kday}^{-1}\end{array}$ & $\begin{array}{l}\text { Standard } \\
\text { atmosphere, } \\
\text { Kday }^{-1}\end{array}$ & $\begin{array}{c}\text { Actual } \\
\text { water vapor } \\
\text { atmosphere, } \\
\text { Kday }^{-1}\end{array}$ \\
\hline \multirow[t]{3}{*}{3} & 0.78 & 1 & $20 \pm 2$ & $0.16 \pm 0.02$ & 0.10 & 0.09 \\
\hline & & 2 & $28 \pm 2$ & $0.19 \pm 0.01$ & .08 & .08 \\
\hline & & 3 & $29 \pm 2$ & $0.25 \pm 0.02$ & .06 & .06 \\
\hline \multirow[t]{3}{*}{8} & .13 & 1 & $14 \pm 2$ & $0.11 \pm 0.01$ & .09 & .06 \\
\hline & & 2 & $36 \pm 3$ & $0.24 \pm 0.02$ & .11 & .14 \\
\hline & & 3 & $29 \pm 3$ & $0.25 \pm 0.16$ & .06 & .06 \\
\hline
\end{tabular}

a Layers 1, 2, and 3 refer to atmospheric layers included between the altitudes 7 and $3.9 \mathrm{~km}, 3.9$ and $1.6 \mathrm{~km}$, and 1.6 and $0.03 \mathrm{~km}$, respectively.

bnergy absorption is instantaneous at noon. 
TABLE 5.- HAZE FLUX DENSITY ABSORPTION AND HEATING RATES

\begin{tabular}{lccc}
$\begin{array}{c}\text { AGASP } \\
\text { flight } \\
\text { no. }\end{array}$ & Layer $^{\mathrm{a}}$ & $\begin{array}{c}\text { Haze } \\
\text { heating rates, } \\
\text { Kday }\end{array}$ & $\begin{array}{c}\text { Haze }^{\mathrm{b}} \\
\text { flux density } \\
\text { absorption, } \\
\text { wm }^{-2}\end{array}$ \\
\hline 3 & 1 & $0.06 \pm 0.01$ & $8.0 \pm 0.8$ \\
& 2 & $0.11 \pm 0.05$ & $13.8 \pm 1.0$ \\
& 3 & $0.19 \pm 0.01$ & $23.5 \pm 1.6$ \\
8 & 1 & $0.05 \pm 0.01$ & $6.6 \pm 1.0$ \\
& 2 & $0.10 \pm 0.01$ & $12.7 \pm 1.0$ \\
& 3 & $0.19 \pm 0.02$ & $24.6 \pm 2.5$ \\
\hline
\end{tabular}

$a, b_{\text {See }}$ table 1 . 
TABLE 6.- ALTITUDE AVERAGED HEATING RATES

\begin{tabular}{|c|c|c|}
\hline \multirow{2}{*}{$\begin{array}{l}\text { AGASP } \\
\text { flight } \\
\text { no. }\end{array}$} & \multicolumn{2}{|c|}{$\begin{array}{l}\text { Daily averaged } \\
\text { heating rate, } \text { Kday }^{-1}\end{array}$} \\
\hline & Broadband & Narrow band \\
\hline 3 & 0.20 & 0.17 \\
\hline 8 & .20 & .21 \\
\hline
\end{tabular}

TABLE 7.- BROADBAND FLUX DENSITY ABSORPTION, $\mathrm{W} / \mathrm{m}^{2}$

\begin{tabular}{|c|c|c|c|c|}
\hline \multirow{2}{*}{$\begin{array}{l}\text { Layer } \\
\text { number }\end{array}$} & \multicolumn{2}{|c|}{ Flight no. 3} & \multicolumn{2}{|c|}{ Flight no. 4} \\
\hline & Data & Model & Data & Model \\
\hline 1 & 20 & 21 & 14 & 15 \\
\hline 2 & 28 & 28 & 36 & 37 \\
\hline 3 & 29 & 30 & 29 & 32 \\
\hline Total & 77 & 79 & 79 & 84 \\
\hline
\end{tabular}


Figure 1.- Arctic haze event, March 1983.

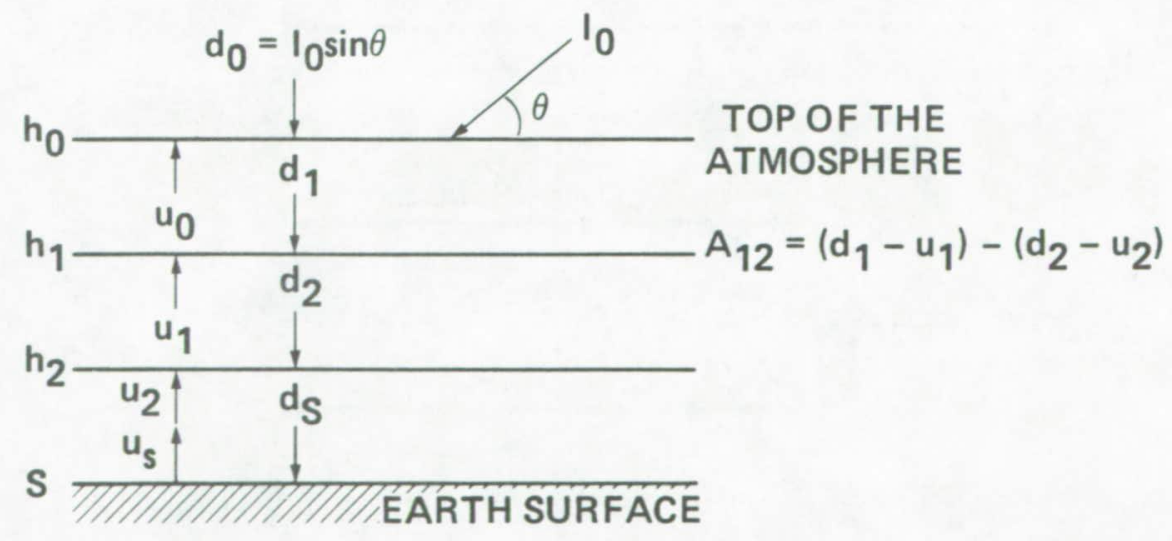

Figure 2.- Method used to measure "in situ" the power absorbed by atmospheric layers. 


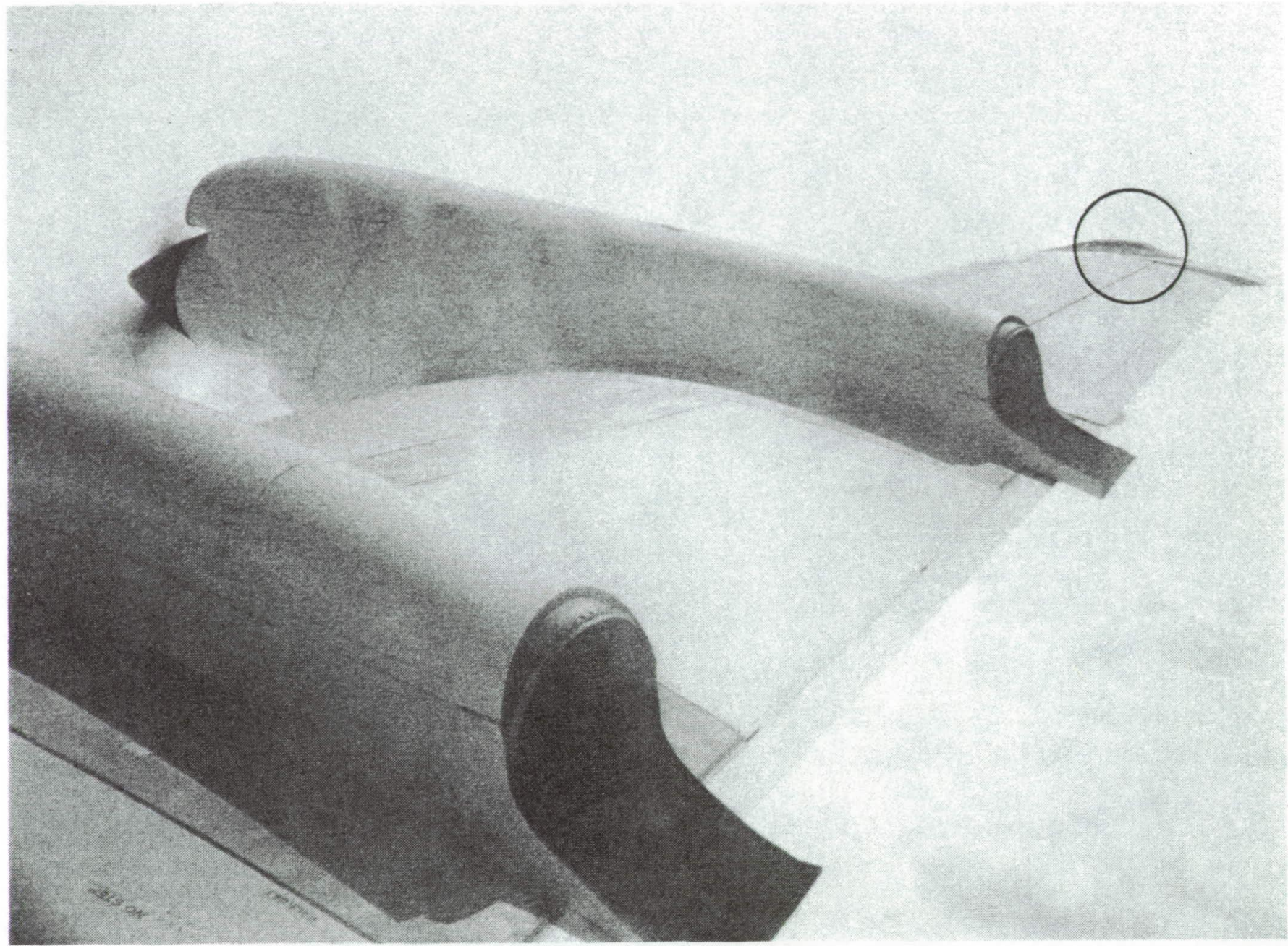

Figure 3.- Radiometric system mounted in the WP-3D research aircraft.

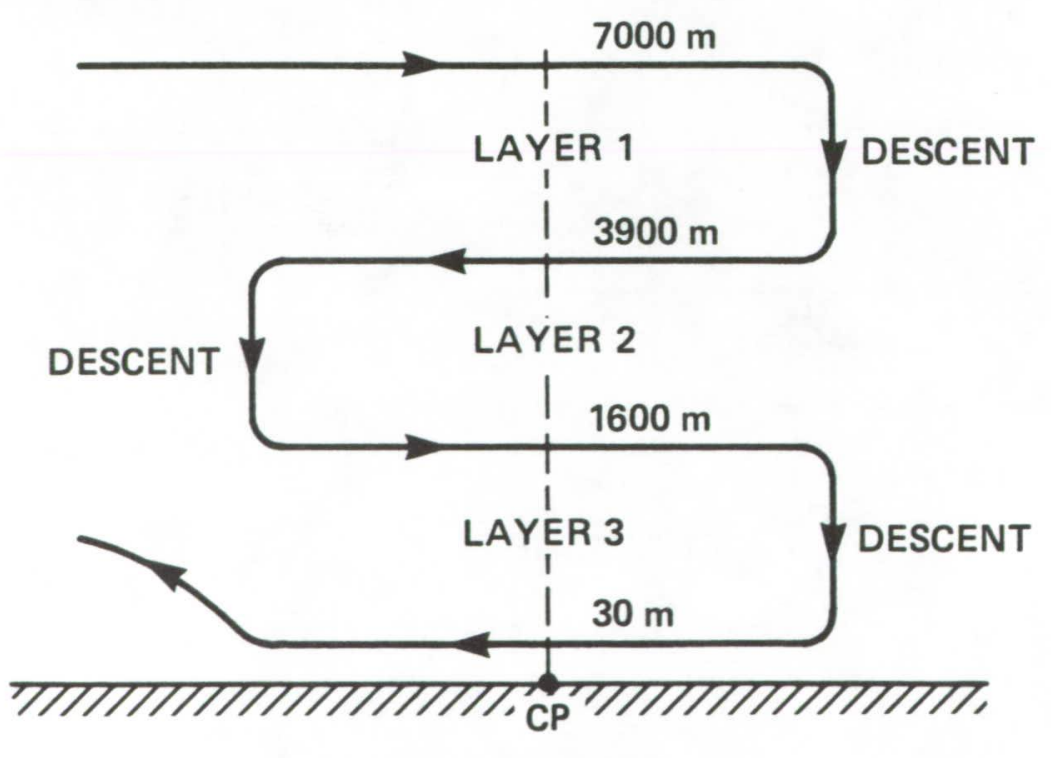

ICE OR WATER

Figure 4.- Flight profiles to measure net radiative fluxes. 

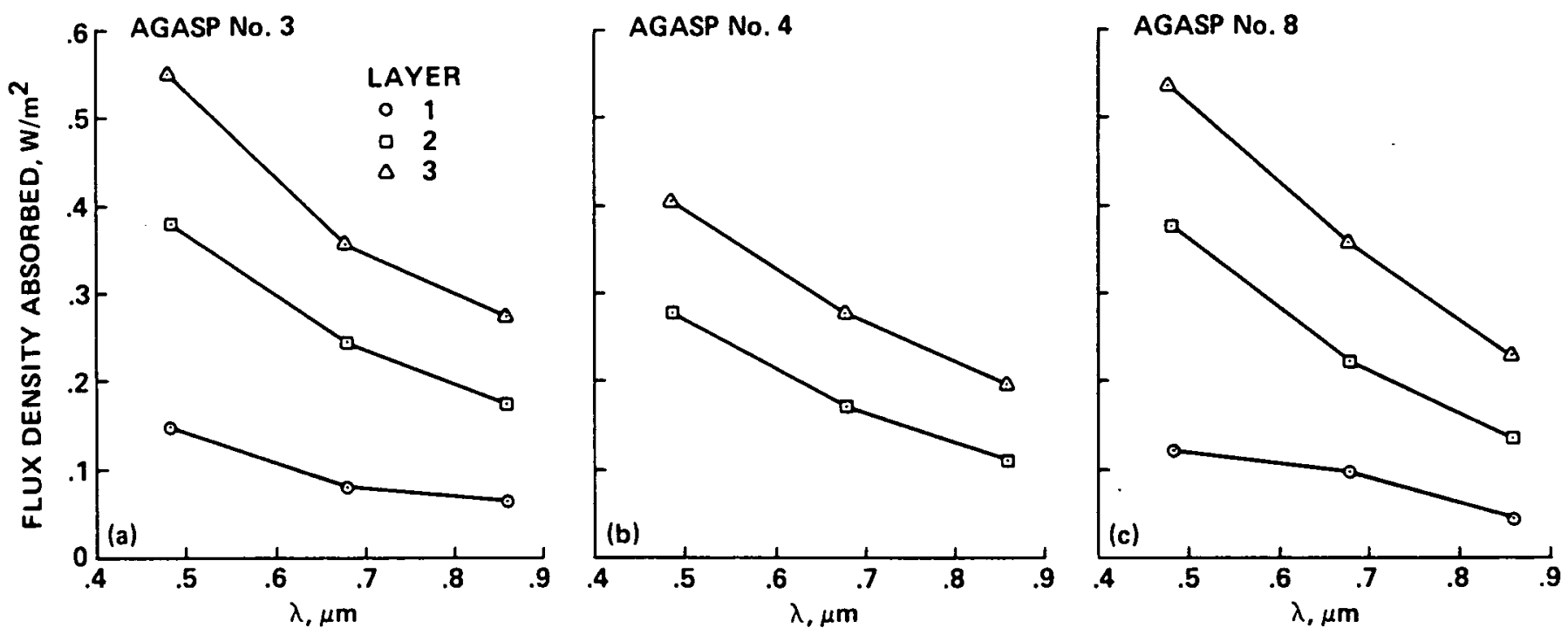

Figure 5.- Radiative power absorbed in $0.01 \mu \mathrm{m}$ spectral bandpasses as a function of wavelength. Layers are defined in Table 1.
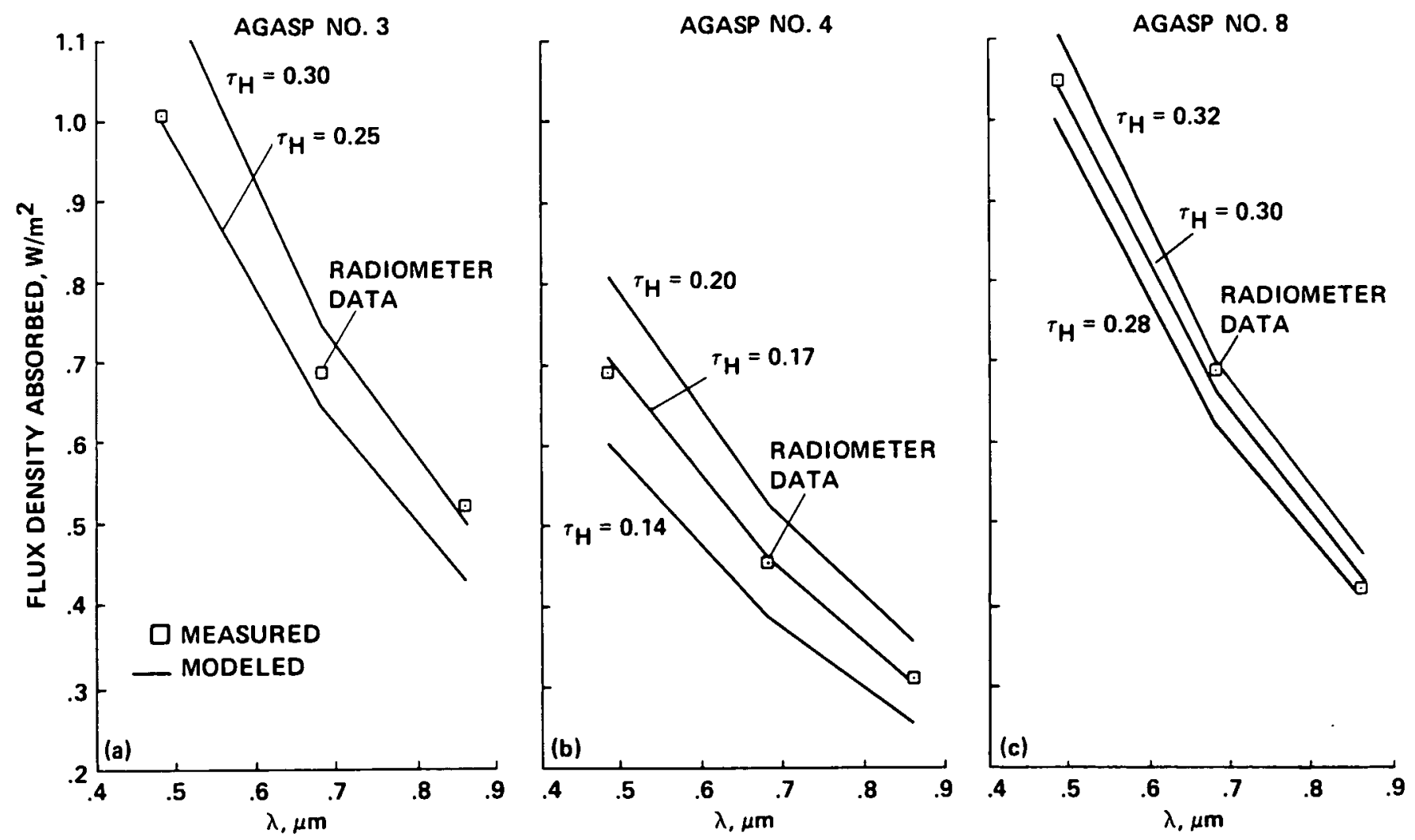

Figure 6.- Measured and calculated total power absorbed by the atmosphere in $0.01 \mu \mathrm{m}$ intervals. $\mathrm{T}_{\mathrm{H}}$ is the extinction optical depth at $500 \mathrm{~nm}$. Symbols are measured values, solid lines represent model results. 

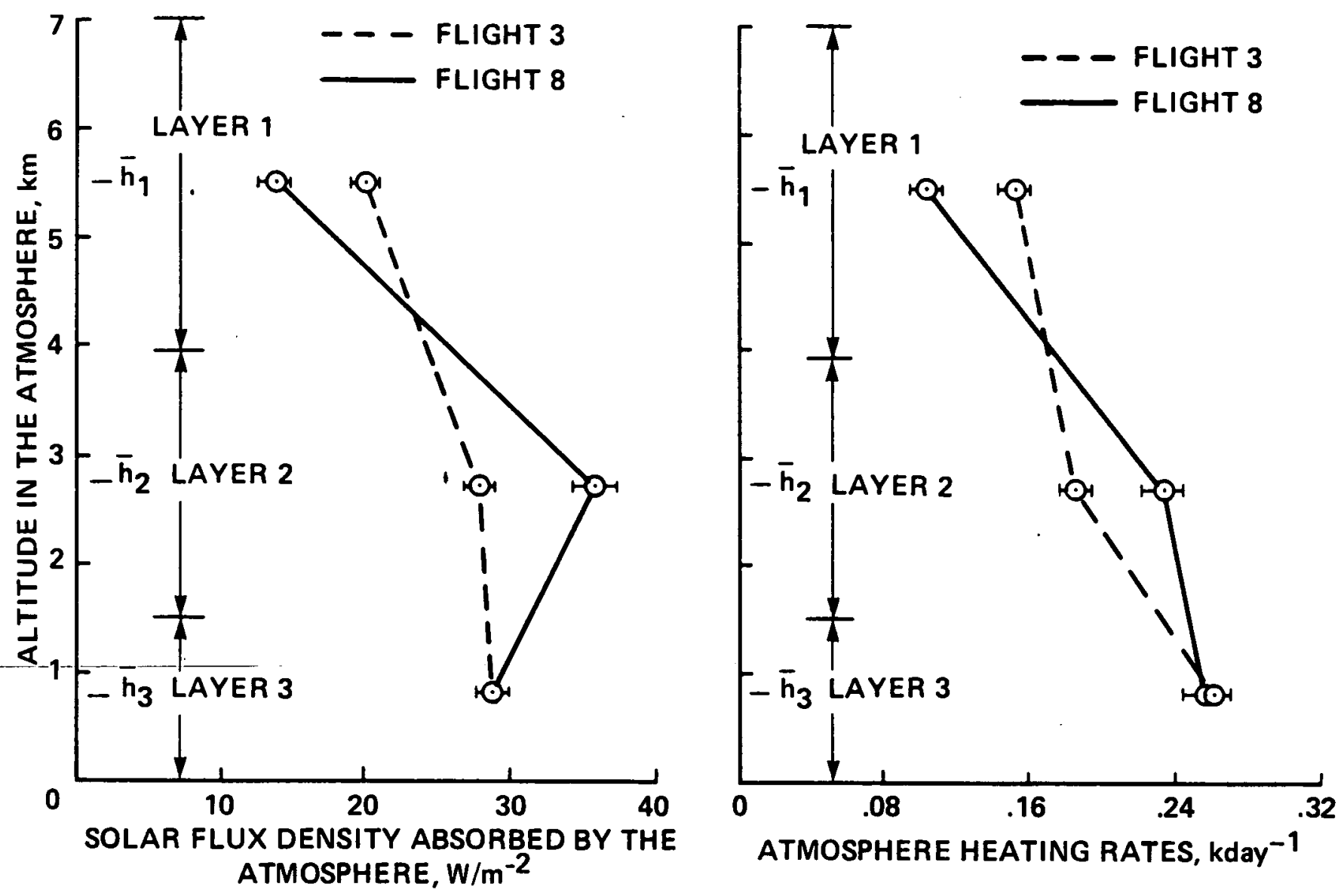

Figure 7.- a) Broadband (260-2600 nm) solar radiation absorbed by the polluted arctic atmosphere. b) Daily averaged heating rates as a function of altitude. 

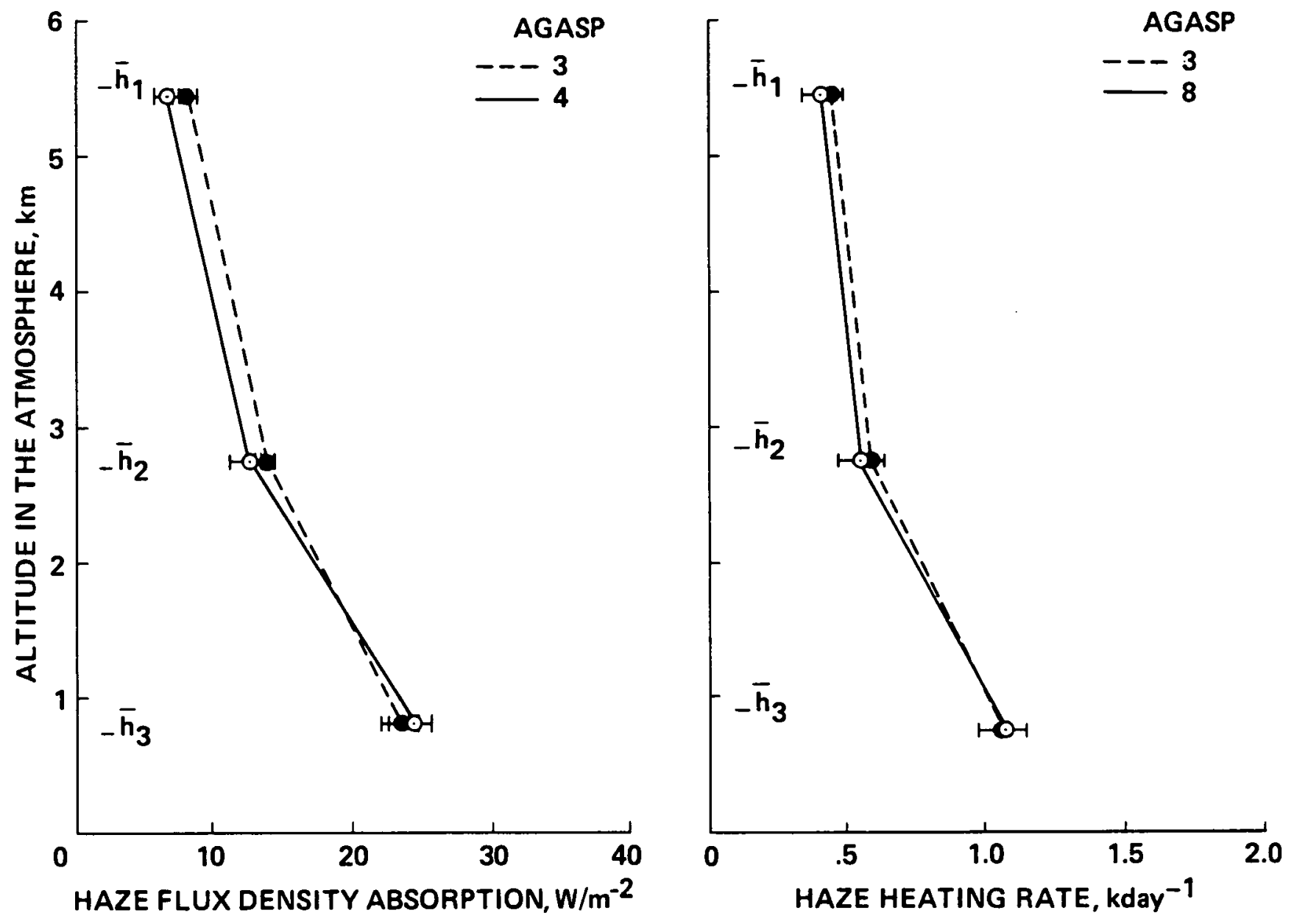

Figure 8.- a) Energy absorbed by the haze in the 260-2600 nm interval. b) Corresponding heating rates. 
AGASP FLIGHT NO. 3

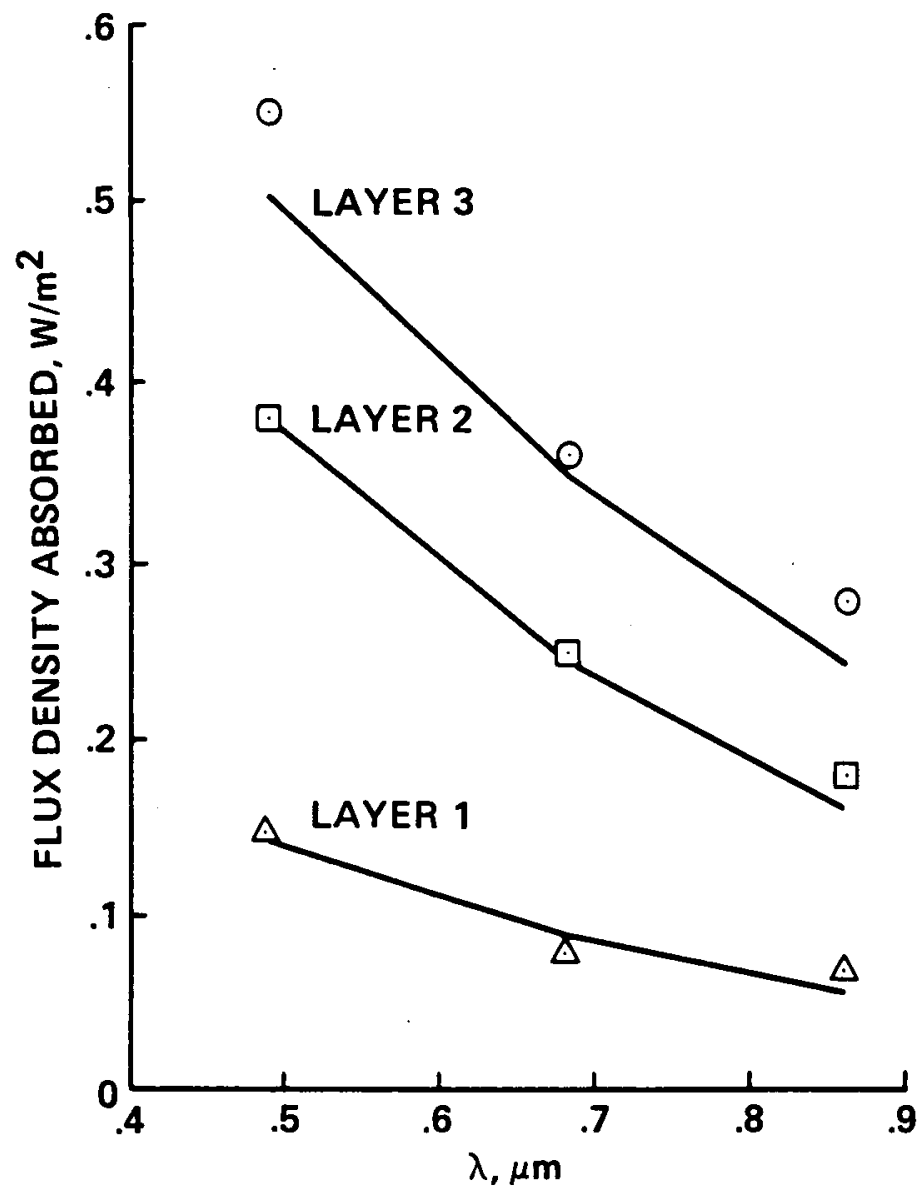

AGASP FLIGHT NO. 8

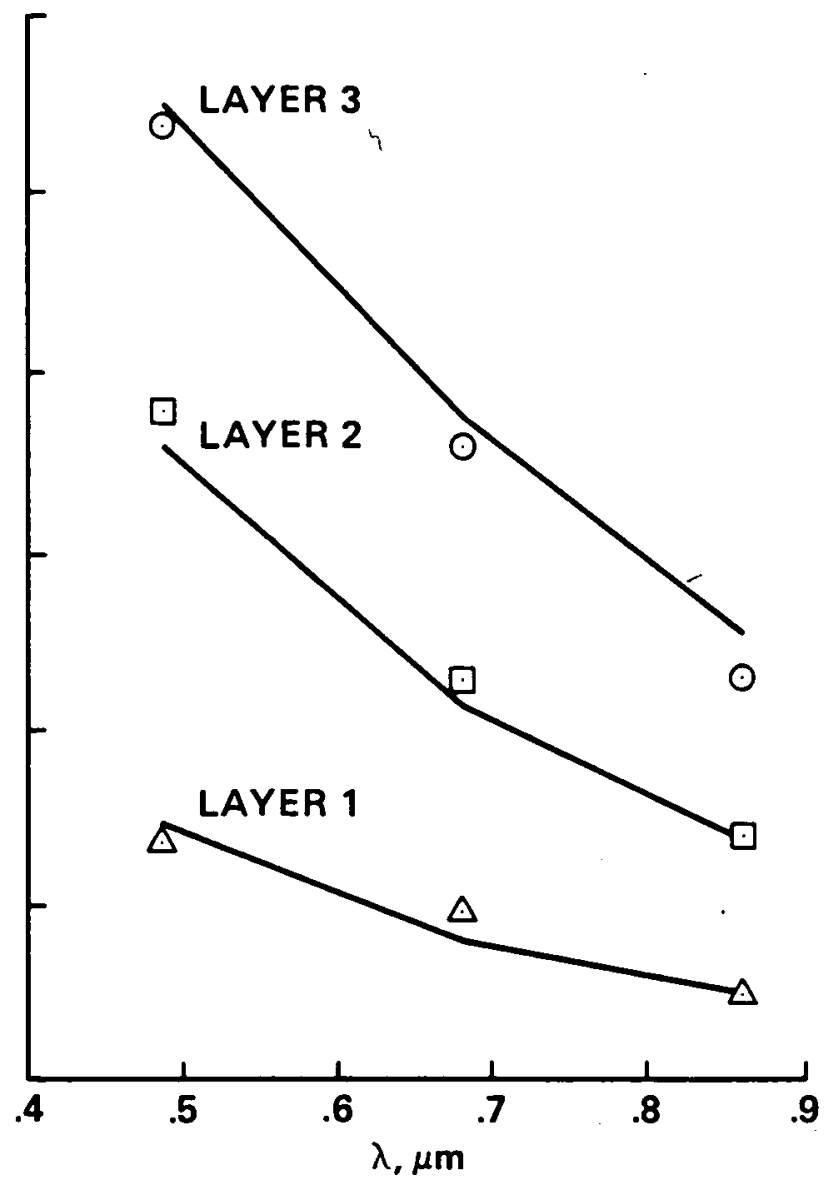

Figure 9.- Power absorbed in bandpasses in each atmospheric layer. Symbols are measured values, solid lines represent model results.

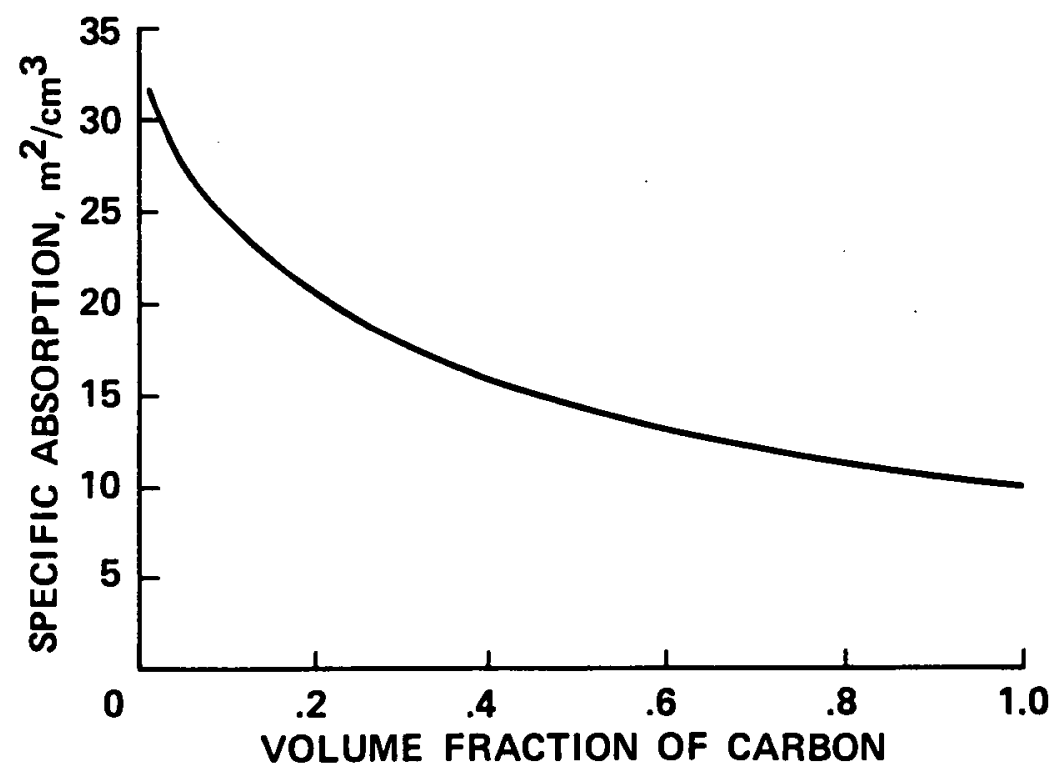

Figure 10.- Specific absorption per unit volume of carbon as a function of volume fraction of carbon. 


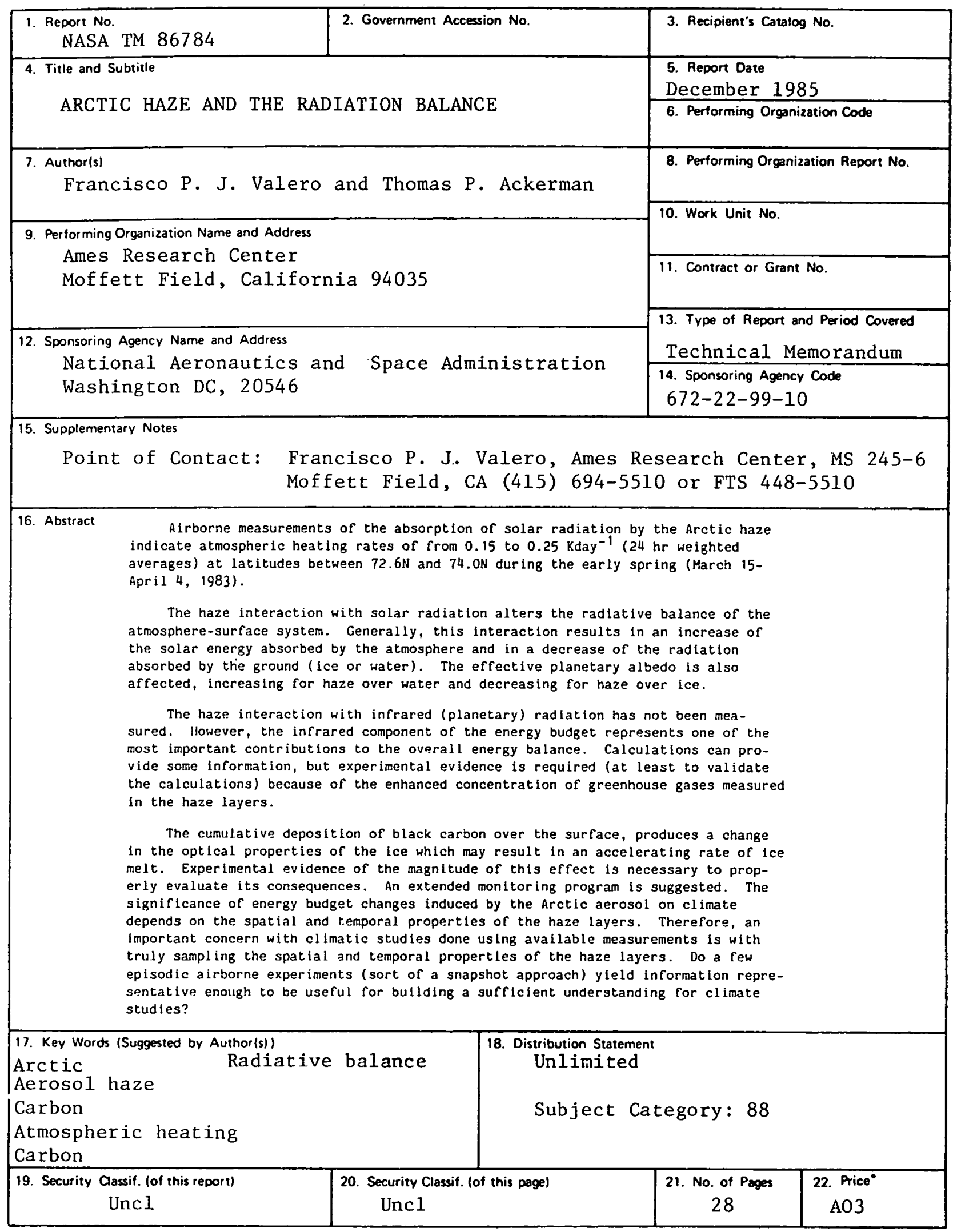

-For sale by the National Technical Information Service, Springfiald, Virginia 22161 